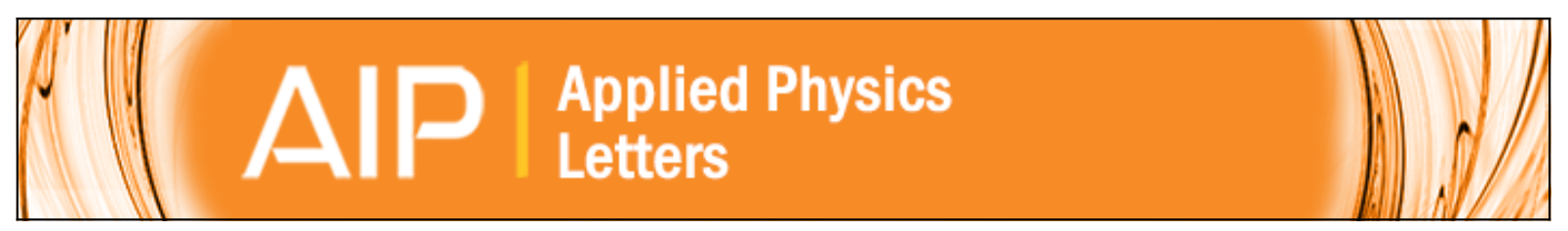

Degeneration of amyloid- $\beta$ fibrils caused by exposure to low-temperature atmosphericpressure plasma in aqueous solution

Eisuke Takai, Gai Ohashi, Tomonori Yoshida, Karin Margareta Sörgjerd, Tamotsu Zako, Mizuo Maeda, Katsuhisa Kitano, and Kentaro Shiraki

Citation: Applied Physics Letters 104, 023701 (2014); doi: 10.1063/1.4861842

View online: http://dx.doi.org/10.1063/1.4861842

View Table of Contents: http://scitation.aip.org/content/aip/journal/apl/104/2?ver=pdfcov

Published by the AIP Publishing 


\title{
Degeneration of amyloid- $\beta$ fibrils caused by exposure to low-temperature atmospheric-pressure plasma in aqueous solution
}

\author{
Eisuke Takai, ${ }^{1}$ Gai Ohashi, ${ }^{1}$ Tomonori Yoshida, ${ }^{2,3}$ Karin Margareta Sörgjerd, ${ }^{2, a)}$ \\ Tamotsu Zako, ${ }^{2}$ Mizuo Maeda, ${ }^{2,3}$ Katsuhisa Kitano, ${ }^{4}$ and Kentaro Shiraki ${ }^{1, b)}$ \\ ${ }^{1}$ Faculty of Pure and Applied Science, University of Tsukuba, 1-1-1 Tennodai, Tsukuba, Ibaraki 305-8573, \\ Japan \\ ${ }^{2}$ Bioengineering Laboratory, RIKEN, 2-1 Hirosawa, Wako, Saitama 351-0198, Japan \\ ${ }^{3}$ Department of Advanced Materials Science, School of Frontier Sciences, The University of Tokyo, 5-1-5, \\ Kashiwanoha, Kashiwa, Chiba 227-8561, Japan \\ ${ }^{4}$ Center for Atomic and Molecular Technologies, Graduate School of Engineering, Osaka University, \\ Osaka 565-0871, Japan
}

(Received 22 October 2013; accepted 26 December 2013; published online 13 January 2014)

Low-temperature atmospheric-pressure plasma was applied to degenerate amyloid- $\beta$ (Aß) fibrils, which are a major component of neuritic plaque associated with Alzheimer's disease (AD). We showed that an $\mathrm{A} B$ fibril exposed to a low-frequency (LF) plasma jet in aqueous solution retained its morphology, molecular weight, and cytotoxicity, but, intriguingly, decreased in protease resistance and $\beta$-sheet content. These results suggested that an LF plasma jet could be utilized for the treatment of $\mathrm{AD}$ to eliminate neuritic plaque by accelerating the proteolysis of $\mathrm{A} \beta$ fibrils. (c) 2014 AIP Publishing LLC. [http://dx.doi.org/10.1063/1.4861842]

Low-temperature atmospheric-pressure plasma (LTAPP) generates reactive oxygen species (ROS), ${ }^{1}$ typically hydroxyl radicals $(\mathrm{OH} \cdot),{ }^{2-6}$ superoxide anion radicals $\left(\mathrm{O}_{2}{ }^{-} \cdot\right),{ }^{7}$ hydroperoxyl radicals (HOO-) ${ }^{8}$ singlet oxygen $\left({ }^{1} \mathrm{O}_{2}\right)$, and atomic oxygen $(\mathrm{O})^{9}$ in the gas phase. It has been reported that the plasma processing of solids is useful in producing surface coatings for biomedical materials. ${ }^{10-12}$ In contrast, once LTAPP is exposed to a solution, advanced reaction fields are induced inside the liquid because some of the plasma-induced ROS diffuse into the solution. This feature of LTAPP processing allows the exploitation of a type of chemical reactions in solution. ${ }^{13-15}$ Because organisms also present aqueous conditions, this phenomenon is expected to inform the development of plasma medicines ${ }^{16,17}$ for cancer, ${ }^{18-21}$ glioma, ${ }^{22}$ dentistry, ${ }^{23}$ blood coagulation, ${ }^{24}$ disruption of the human hepatocyte cytoskeleton, ${ }^{25}$ sterilization, ${ }^{26-35}$ and Parkinson's disease. ${ }^{36}$ In this letter, we examine the application possibilities of LTAPP for the treatment of Alzheimer's disease (AD), which is a progressive neurodegenerative disorder characterized by memory loss and dementia that was reported by Alois Alzheimer in 1906; it is the most common cause of dementia in elderly people, accounting for more than $15 \times 10^{6}$ cases worldwide. ${ }^{37,38}$

For the present study, a low-frequency (LF) plasma jet was used for the LTAPP processing in a manner similar to that described in our previous study. ${ }^{8,34,39}$ The plasma shape was elongated from the end of a quartz glass tube, in which helium gas flowed, by the application of an alternatingcurrent high voltage (ranging from -3.5 to $+5.0 \mathrm{kV}$ at a frequency of $13.9 \mathrm{kHz}$ ) to a single-sided electrode (Fig. 1(a)). Helium plasma with a low gas temperature was generated in an elongated shape (Fig. 1(b)). The discharge power of the

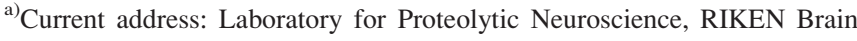
Science Institute, 2-1 Hirosawa, Wako, Saitama 351-0198, Japan.

b) Author to whom correspondence should be addressed. Electronic mail: shiraki@bk.tsukuba.ac.jp. Tel.: +81 29 8535306. Fax: +81298535215.
}

plasma was $3 \mathrm{~W}$. The LF plasma jet was generated inside an airtight chamber from its center port. The ambient gas of the chamber could be controlled using the other oxygen $\left(\mathrm{O}_{2}\right)$ gas supply port connected to the side of the plasma-jet port. The flow rates of $\mathrm{He}$ and $\mathrm{O}_{2}$ gas were 0.50 and $0.15 \mathrm{l} / \mathrm{min}$, respectively. Various active oxygen species produced from the $\mathrm{O}_{2}$ gas by the plasma were supplied to the solution.

Amyloid fibrils of human protein $A B$ were prepared in vitro. Briefly, lyophilized Aß1-40 from Peptide Institute Inc., Osaka, Japan was dissolved in phosphate-buffered saline (PBS; $100 \mathrm{mM} \mathrm{NaCl}, 50 \mathrm{mM} \mathrm{Na}$-phosphate buffer at $\mathrm{pH}$ 7.4), and then the sample was incubated at $37^{\circ} \mathrm{C}$ for 5 days. As expected, typical mature $\mathrm{A} \beta$ fibrils were formed, which are characterized by (i) a sigmoidal evolution of the

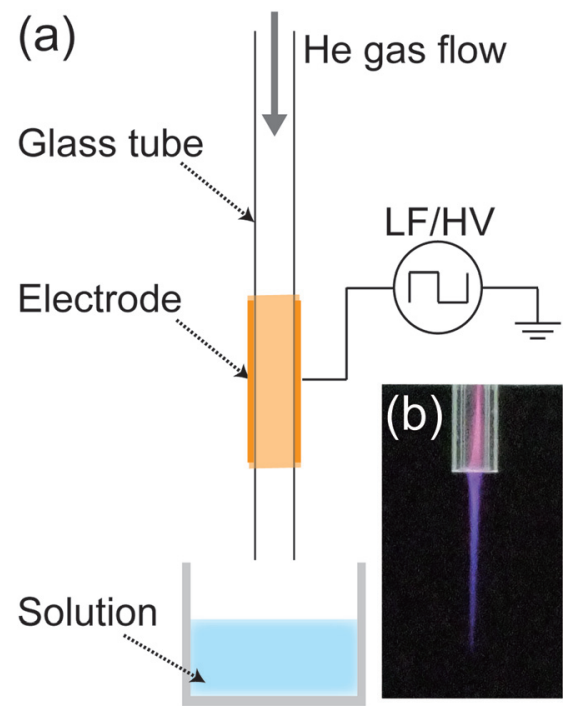

FIG. 1. Plasma jet generated using helium gas flowing through quartz glass tube. (a) Schematic representation of the plasma-jet system with sample solution. The plume-like structure of the plasma extends toward the surface of the sample solution. (b) Photograph of the plasma jet. 
Thioflavine $\mathrm{T}$ (ThT) fluorescent intensity with a lag time of 1-2 days (Fig. S1a in supplementary material ${ }^{48}$ ), (ii) linear protein aggregates visualized via transmission electron microscopy (TEM) with stain (Fig. S1a, inset in supplementary mate$\mathrm{rial}^{48}$ ), and (iii) a $B$-sheet structure identified by a negative peak at $218 \mathrm{~nm}$ in the far-UV circular dichroism (CD) spectra (Fig. S1b in supplementary material ${ }^{48}$ ). The $\mathrm{A} \beta$ fibril solution was treated with an LF plasma jet (Fig. 1). Then, the plasmaexposed $A \beta$ fibrils were analyzed using several biochemical and biophysical methods to detect changes in physiological activity. These experimental procedures and systems are described in detail in the supplementary material. ${ }^{48}$

The morphology, length, aggregation extent, and molecular weight of the plasma-exposed fibrils were investigated. Figures 2(a) and 2(b) show TEM images of fibrils that were exposed to the plasma for 0 and $30 \mathrm{~min}$, respectively. The $\mathrm{A} \beta$ fibrils that were exposed for $30 \mathrm{~min}$ were observed to be non-branched fibrils of more than $1 \mu \mathrm{m}$ in length, similar to the untreated fibrils $(0 \mathrm{~min})$. The length distributions of the plasma-exposed fibrils for 0 and $30 \mathrm{~min}$ were almost identical, indicating that the $A B$ fibrils were not fragmented by plasma exposure in solution (Figs. 2(c) and 2(d)). This result was supported by a native poly-acrylamide gel electrophoresis (PAGE)/Western-blotting analysis, which showed that there were no soluble oligomeric species in the plasmaexposed fibril samples (Fig. 2(e)). The aggregation extent of the $A ß$ fibrils was monitored via light scattering at $350 \mathrm{~nm}$, which is sensitive to the number and size of aggregates present in a solution, as reported previously. ${ }^{40,41}$ The lightscattering intensity was proportional to the concentration of $\mathrm{A} \beta$, but it was unchanged by the plasma exposure (Fig. 2(f)). These results demonstrated that the morphology, length, molecular weight, and aggregation extent of the $A ß$ fibrils were unchanged by plasma exposure for a duration of several minutes. In contrast, it has been reported that amyloid fibrils of $\alpha$-synuclein were fragmented by $6 \mathrm{~min}$ of exposure to a low-temperature plasma jet in solution. ${ }^{36}$ These differing results may be attributable to the difference in the structural stability of the amyloid fibrils. ${ }^{42}$

The cytotoxicity of the plasma-exposed $A \beta$ fibrils on a rat pheochromocytoma PC12 cell was examined using an 3(4,5-di-methylthiazol-2-yl)-2,5-diphenyltetrazolium bromide (MTT) assay, as previously described. ${ }^{43}$ First, we demonstrated that the plasma-exposed PBS without A $\mathrm{A}$ also exhibited cytotoxicity (Fig. 3(a)) because of the hydrogen peroxide generated by a plasma-inactivated culture cell. ${ }^{18}$ To overcome this problem, catalase, which is an enzyme that catalyzes the decomposition of hydrogen peroxide to water and oxygen, was added to the sample solution to avoid the confounding influence of hydrogen peroxide in the cytotoxicity assay (Fig. 3(a)). Figure 3(b) shows the cytotoxicity of plasma-exposed $A \beta$ fibrils with the inclusion of catalase,

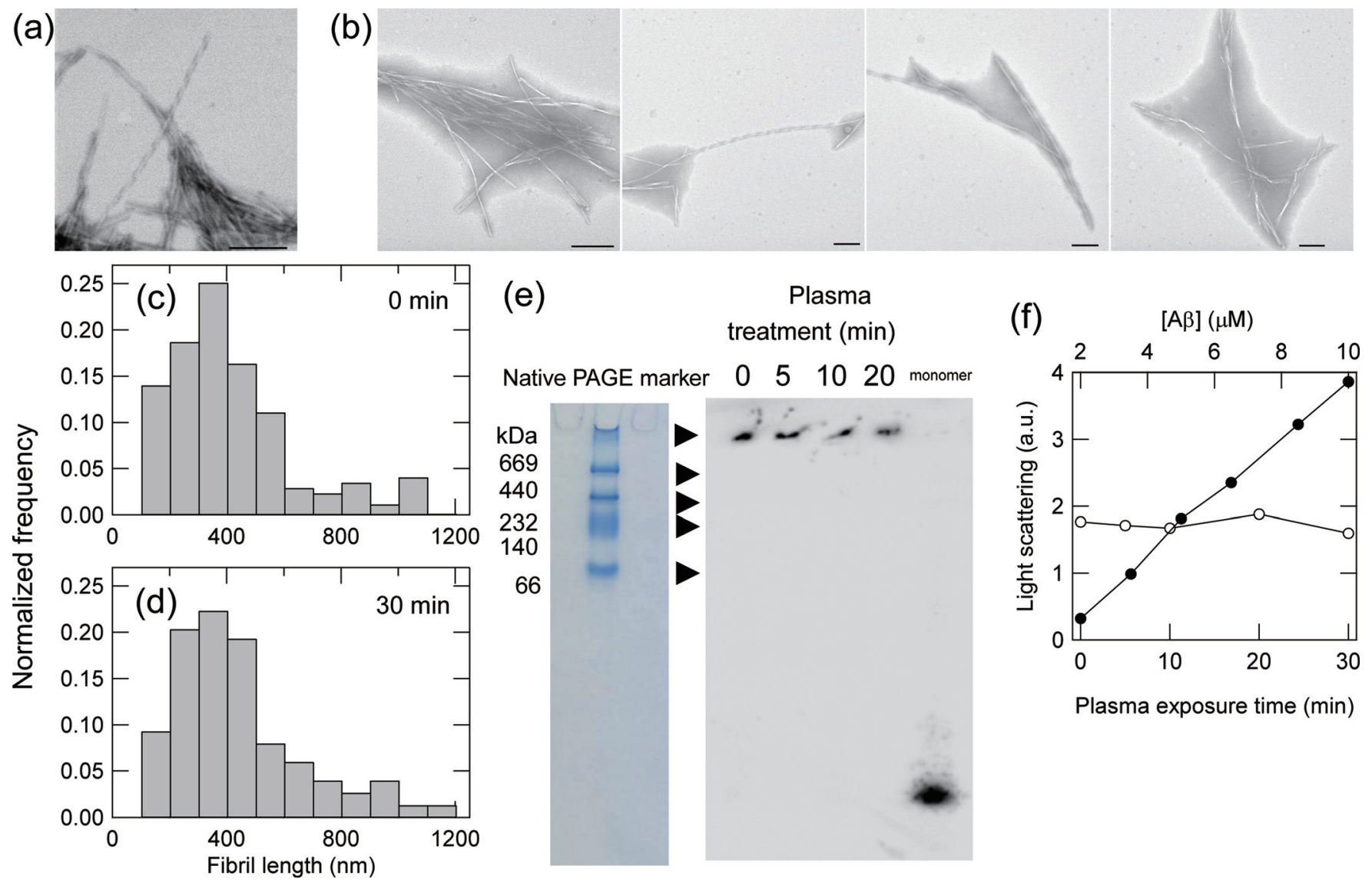

FIG. 2. Characterization of A $\beta$ fibrils exposed to an LF plasma jet. Morphology of A $\beta$ fibrils (a) before and (b) after the plasma exposure (30 min) as imaged via TEM. The scale bars represent $200 \mathrm{~nm}$. Contour-length distribution of A $\beta$ fibrils (c) before and (d) after the plasma exposure, calculated from TEM images. The sampling numbers were 150 in (c) and 171 in (d). (e) Native PAGE/Western-blotting analysis of A $\beta$ fibrils exposed to an LF plasma jet using mouse monoclonal anti-A $\beta$ (6E10). Unincubated $\mathrm{A} \beta$ monomers were used as a control. (f) Light scattering at $350 \mathrm{~nm}$ as a function of the $\mathrm{A} \beta$ concentration (closed circles, top axis) and the plasma-exposure time (open circles, bottom axis). 

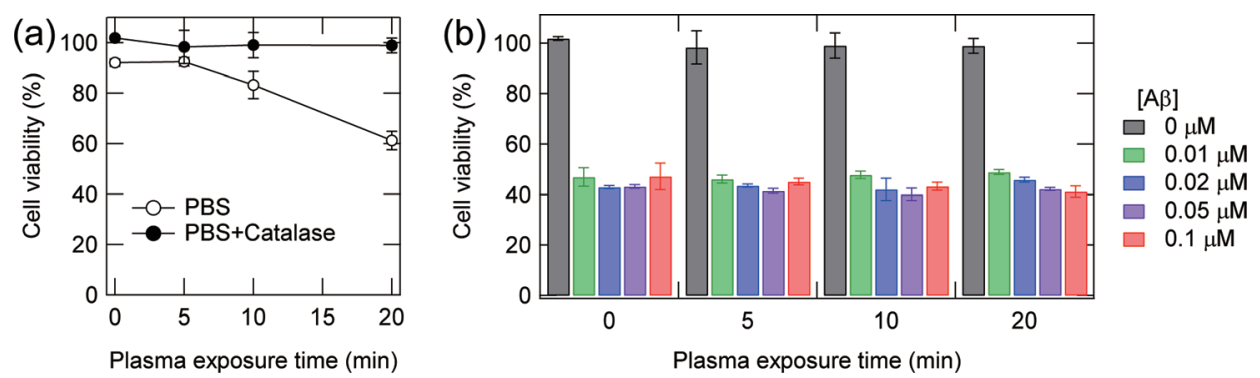

FIG. 3. Cytotoxicity assays of the plasma-treated samples with PC12 cells using an MTT assay. (a) Cytotoxicity assays of plasma-treated PBS without A $\beta$ in the absence (open circles) or presence (closed circles) of $2 \mu \mathrm{g} / \mathrm{ml}$ of catalase. The catalase was added after plasma exposure and before the cytotoxicity assays. (b) Cytotoxicity assays of $\mathrm{A} \beta$ as a function of the exposure time with the addition of $2 \mu \mathrm{g} / \mathrm{ml}$ of catalase after plasma exposure.

which was added after plasma exposure. The $A B$ fibrils without plasma exposure exhibited high cytotoxicity. The $A B$ fibrils that were exposed to plasma for 5-20 min also exhibited high cytotoxicity. Thus, it could be concluded that the cytotoxicity of the $A ß$ fibrils was not changed by plasma exposure for a duration of several minutes.

The protease-resistant property of the plasma-exposed fibrils was examined using trypsin, which is a serine protease that cleaves peptide chains at the carboxyl end of the amino acids lysine and arginine. ${ }^{44}$ Figure $4($ a) shows the lightscattering intensity of the plasma-exposed fibrils after the trypsin treatment. The light-scattering intensity of the $A B$ fibrils decreased with increasing plasma-exposure time, indicating that the protease resistance of the $A B$ fibrils was decreased by the plasma treatment. The decrease of the protease resistance of the plasma-treated $\mathrm{A} \beta$ fibrils was confirmed by using other proteases (Fig. S2 in supplementary material $^{48}$ ). The degradation of the plasma-exposed fibrils by trypsin was confirmed via atomic force microscopy (AFM) (Figs. 4(b) and 4(c)). The degraded Aß fibrils were primarily observed as spherical aggregates (Fig. 4(b)), which may consist of insoluble peptides of $A B$ formed via proteolysis. In contrast, the $A ß$ fibrils that were not exposed to the plasma

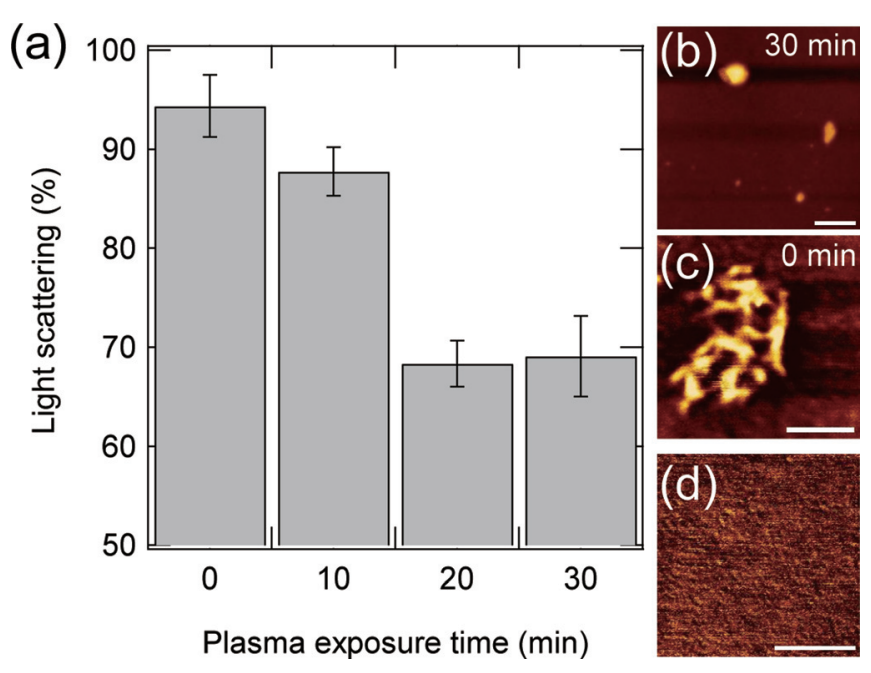

FIG. 4. Evaluation of the protease resistance of $\mathrm{A} \beta$ fibrils exposed to an LF plasma jet. (a) Light-scattering intensity at $350 \mathrm{~nm}$ of $\mathrm{A} \beta$ fibrils incubated with trypsin for $24 \mathrm{~h}$ as a function of the plasma-exposure time. The lightscattering intensity of $100 \%$ was defined by the measurement of a sample of unexposed $\mathrm{A} \beta$ fibrils without trypsin digestion. AFM images of the $\mathrm{A} \beta$ fibrils that were exposed to the plasma for (b) $30 \mathrm{~min}$ and (c) $0 \mathrm{~min}$ and incubated with trypsin for $24 \mathrm{~h}$. (d) AFM image of the $\mathrm{A} \beta$ before incubation. The scale bars represent $200 \mathrm{~nm}$. remained as fibrillar aggregates even after the trypsin treatment (Fig. 4(c)). No aggregates of the $A ß$ peptides before incubation were observed (Fig. 4(d)). These results demonstrated that the protease resistance of the $A ß$ fibrils was degraded by plasma exposure.

To elucidate the mechanism of the loss of the protease resistance of the $A B$ fibrils caused by plasma exposure, we examined the structural properties of the plasma-exposed $A B$ fibrils via far-UV CD spectroscopy to determine the B-sheet content and via fluorescence assay with thioflavin $\mathrm{T}$ (ThT) to determine the amount of accumulated cross- $\beta$ structure and 8-anilino-1-naphthalenesulfonic acid (ANS) to understand the surface hydrophobicity (Fig. 5). The peak at $218 \mathrm{~nm}$ in the $\mathrm{CD}$ spectrum decreased in intensity with increasing plasma-exposure time, indicating that the regular cross- $\beta$ structure of the $A ß$ fibrils ${ }^{45}$ was destroyed by plasma exposure. The intensity at $218 \mathrm{~nm}$ of the plasma exposed $\mathrm{A} \beta$ fibrils was unchanged even after incubation at $37^{\circ} \mathrm{C}$ for 24-72 h (Fig. 5(a), inset), indicating that there is no recovery of $\mathrm{A} \beta$ fibrils from the damages unlike living cells. The ThT fluorescence intensity decreased with increasing plasmaexposure time (Fig. 5(b)), which is consistent with the results from the CD spectra (Fig. 5(a)), indicating the unfolding of the $\beta$-sheet core in the $\mathrm{A} \beta$ fibrils as a result of the plasma exposure. The ANS fluorescence of the plasma-exposed AB fibrils was quenched (Fig. 5(c)), which indicates that the surface hydrophobicity of the $A B$ fibrils was decreased by the plasma exposure. These results suggest that the degeneration of $A B$ fibrils induced by plasma exposure might cause the loss of their protease-resistant property.

Plasma exposure in solution induces chemical reaction fields not only on the surface of the liquid but also inside the liquid itself because of the diffusion of ROS generated in the gas phase. These species should react with $A ß$ fibrils. In fact, some amino-acid residues of $\mathrm{A} B$ peptides, such as methionine, tyrosine, and histidine, are oxidized by the ROS generated via laser irradiation in solution. ${ }^{46}$ We have previously reported that chemical modifications of amino-acid residues induced the denaturation and inactivation of proteins via plasma exposure in solution. ${ }^{39}$ Therefore, it is plausible that chemical reactions of the amino-acid residues with the ROS generated by plasma may result in the degeneration of $A B$ fibrils and the loss of their protein-resistant property.

It was demonstrated that the protease resistance, $B$-sheet structure, and surface properties of $A B$ fibrils were changed by LTAPP processing in aqueous solution while the morphology, length, and cytotoxicity remained unchanged. In a 

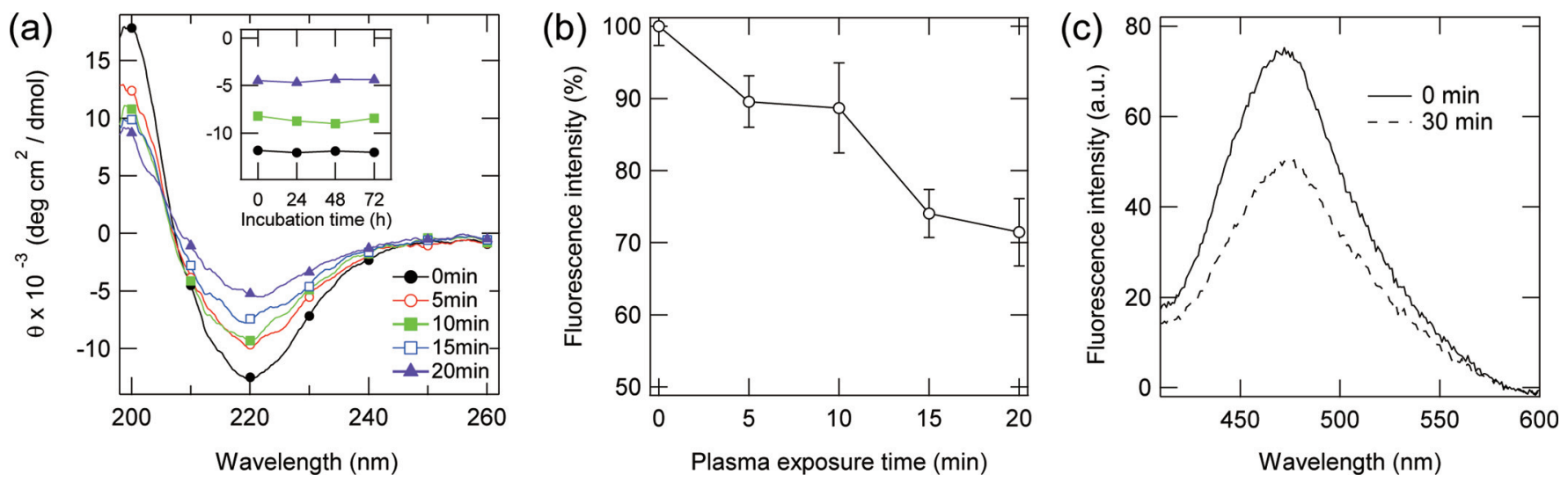

FIG. 5. (a) Circular dichroism spectra of $\mathrm{A} \beta$ fibrils exposed to an LF plasma jet for various durations. Inset: The intensity at 218 nm of the $\mathrm{A} \beta$ fibrils incubated at $37^{\circ} \mathrm{C}$ after the plasma exposure. (b) ThT fluorescence intensity of $\mathrm{A} \beta$ fibrils as a function of the plasma-exposure time. The fluorescence emission at 480 $\mathrm{nm}$ was measured for excitation at $420 \mathrm{~nm}$. (c) ANS fluorescence spectra of the A $\beta$ fibrils before and after plasma exposure for 30 min. The samples were excited at $370 \mathrm{~nm}$.

previous study, the degradation of $A ß$ fibrils induced by direct LTAPP treatment on a solid surface has been reported. ${ }^{47}$ Any species can act in direct LTAPP treatment; on the other hand, only soluble and long-lived species, such as HOO., can attack in LTAPP processing in aqueous solution. ${ }^{34}$ Therefore, the seemingly contradictory results of the two studies might be attributable to the difference in the amount and type of ROS attacking the AB fibrils.

In conclusion, we demonstrated that LTAPP treatment caused the degeneration of $A B$ fibrils, which are a major component of the neuritic plaque associated with $\mathrm{AD}$, in terms of accumulated $B$-sheet content and protease resistance, while the morphology, contour length, and cytotoxicity of the Aß fibrils remained unchanged. The loss of the protease resistance of the $A ß$ fibrils caused by plasma exposure suggests prospects for utilizing LTAPP for the elimination of neuritic plaque associated with $\mathrm{AD}$ by accelerating the proteolysis of $\mathrm{A} B$ fibrils.

The authors acknowledge financial support from the Ministry of Education, Culture, Sports, Science, and Technology (MEXT), Japan, for Grant-in-Aid for Scientific Research (A) No. 23246063, Research (B) No. 23340176, Research (C) Nos. 23550189 and 24570143, Grant-in-Aid for Scientific Research on Innovative Areas "Plasma Medical Innovation" (25108505) and RIKEN. ET is a Japan Society for the Promotion of Science (JSPS) Fellow.

${ }^{1}$ P. Bruggeman, F. Iza, D. Lauwers, and Y. A. Gonzalvo, J. Phys. D: Appl. Phys. 43(1), 012003 (2010).

${ }^{2}$ B. R. Locke, M. Sato, P. Sunka, M. R. Hoffmann, and J. S. Chang, Ind. Eng. Chem. Res. 45(3), 882-905 (2006).

${ }^{3}$ M. Sahni and B. R. Locke, Plasma Process. Polym. 3(9), 668-681 (2006).

${ }^{4}$ M. Sahni and B. R. Locke, Ind. Eng. Chem. Res. 45(17), 5819-5825 (2006).

${ }^{5}$ P. Bruggeman and C. Leys, J. Phys. D: Appl. Phys. 42(5), 053001 (2009).

${ }^{6}$ R. Burlica, K. Y. Shih, and B. R. Locke, Ind. Eng. Chem. Res. 49(14), 6342-6349 (2010).

${ }^{7}$ A. Tani, Y. Ono, S. Fukui, S. Ikawa, and K. Kitano, Appl. Phys. Lett. 100(25), 254103 (2012).

${ }^{8}$ S. Ikawa, K. Kitano, and S. Hamaguchi, Plasma Process. Polym. 7(1), 33-42 (2010).

${ }^{9}$ D. X. Liu, M. Z. Rong, X. H. Wang, F. Iza, M. G. Kong, and P. Bruggeman, Plasma Process. Polym. 7(9-10), 846-865 (2010).

${ }^{10} \mathrm{P}$. Favia, Surf. Coat. Technol. 211, 50-56 (2012).

${ }^{11}$ R. Di Mundo, R. Gristina, E. Sardella, F. Intranuovo, M. Nardulli, A. Milella, F. Palumbo, R. d'Agostino, and P. Favia, Plasma Process. Polym. 7(3-4), 212-223 (2010).
${ }^{12}$ L. Detomaso, R. Gristina, G. S. Senesi, R. d'Agostino, and P. Favia, Biomaterials 26(18), 3831-3841 (2005).

${ }^{13}$ H. Furusho, D. Miyamoto, Y. Nagasaki, K. Kitano, and S. Hamaguchi, J. Photopolym. Sci. Technol. 20(2), 229-233 (2007).

${ }^{14}$ H. Furusho, K. Kitano, S. Hamaguchi, and Y. Nagasaki, Chem. Mater. 21(15), 3526-3535 (2009).

${ }^{15}$ S. Sumitani, H. Murotani, M. Oishi, K. Kitano, S. Hamaguchi, and Y. Nagasaki, J. Photopolym. Sci. Technol. 22(4), 467-471 (2009).

${ }^{16}$ M. G. Kong, G. Kroesen, G. Morfill, T. Nosenko, T. Shimizu, J. van Dijk, and J. L. Zimmermann, New J. Phys. 11(11), 115012 (2009).

${ }^{17}$ N. Y. Babaeva and M. J. Kushner, J. Phys. D: Appl. Phys. 46(2), 025401 (2013).

${ }^{18}$ T. Sato, M. Yokoyama, and K. Johkura, J. Phys. D: Appl. Phys. 44(37), 372001 (2011).

${ }^{19}$ K. Kim, J. D. Choi, Y. C. Hong, G. Kim, E. J. Noh, J.-S. Lee, and S. S. Yang, Appl. Phys. Lett. 98(7), 073701 (2011).

${ }^{20}$ S. J. Kim, T. H. Chung, S. H. Bae, and S. H. Leem, Appl. Phys. Lett. 97(2), 023702 (2010).

${ }^{21}$ C. H. Kim, S. Kwon, J. H. Bahn, K. Lee, S. I. Jun, P. D. Rack, and S. J. Baek, Appl. Phys. Lett. 96(24), 243701 (2010).

${ }^{22}$ M. Vandamme, E. Robert, S. Pesnel, E. Barbosa, S. Dozias, J. Sobilo, S. Lerondel, A. Le Pape, and J. M. Pouvesle, Plasma Process. Polym. 7(3-4), 264-273 (2010).

${ }^{23} \mathrm{H}$. Yamazaki, T. Ohshima, Y. Tsubota, H. Yamaguchi, J. A. Jayawardena, and Y. Nishimura, Dent. Mater. J. 30(3), 384-391 (2011).

${ }^{24}$ G. Fridman, M. Peddinghaus, M. Balasubramanian, H. Ayan, A. Fridman, A. Gutsol, and A. Brooks, Plasma Chem. Plasma Process. 26(4), 425-442 (2006).

${ }^{25}$ B. Gweon, D. Kim, D. B. Kim, H. Jung, W. Choe, and J. H. Shin, Appl. Phys. Lett. 96(10), 101501 (2010).

${ }^{26}$ S. Perni, G. Shama, J. L. Hobman, P. A. Lund, C. J. Kershaw, G. A. Hidalgo-Arroyo, C. W. Penn, X. T. Deng, J. L. Walsh, and M. G. Kong, Appl. Phys. Lett. 90(7), 073902 (2007).

${ }^{27}$ H. Q. Feng, R. X. Wang, P. Sun, H. Y. Wu, Q. Liu, J. Fang, W. D. Zhu, F. T. Li, and J. Zhang, Appl. Phys. Lett. 97(13), 131501 (2010).

${ }^{28}$ R. Bussiahn, R. Brandenburg, T. Gerling, E. Kindel, H. Lange, N. Lembke, K. D. Weltmann, T. von Woedtke, and T. Kocher, Appl. Phys. Lett. 96(14), 143701 (2010).

${ }^{29}$ J. F. Kolb, A. A. H. Mohamed, R. O. Price, R. J. Swanson, A. Bowman, R. L. Chiavarini, M. Stacey, and K. H. Schoenbach, Appl. Phys. Lett. 92(24), 241501 (2008).

${ }^{30}$ X. Zhang, J. Huang, X. Liu, L. Peng, L. Guo, G. Lv, W. Chen, K. Feng, and S.-z. Yang, J. Appl. Phys. 105(6), 063302 (2009).

${ }^{31}$ X. Lu, T. Ye, Y. Cao, Z. Sun, Q. Xiong, Z. Tang, Z. Xiong, J. Hu, Z. Jiang, and Y. Pan, J. Appl. Phys. 104(5), 053309 (2008).

${ }^{32}$ A. Majumdar, R. K. Singh, G. J. Palm, and R. Hippler, J. Appl. Phys. 106(8), 084701 (2009).

${ }^{33}$ R. Burlica, R. G. Grim, K. Y. Shih, D. Balkwill, and B. R. Locke, Plasma Process. Polym. 7(8), 640-649 (2010).

${ }^{34}$ E. Takai, S. Ikawa, K. Kitano, J. Kuwabara, and K. Shiraki, J. Phys. D: Appl. Phys. 46(29), 295402 (2013). 
${ }^{35}$ M. Nagatsu, Y. Zhao, I. Motrescu, R. Mizutani, Y. Fujioka, and A. Ogino, Plasma Process. Polym. 9(6), 590-596 (2012).

${ }^{36}$ E. Karakas, A. Munyanyi, L. Greene, and M. Laroussi, Appl. Phys. Lett. 97(14), 143702 (2010).

${ }^{37}$ M. Jucker and L. C. Walker, Nature 501(7465), 45-51 (2013).

${ }^{38}$ J. Kang, H. G. Lemaire, A. Unterbeck, J. M. Salbaum, C. L. Masters, K. H. Grzeschik, G. Multhaup, K. Beyreuther, and B. Mullerhill, Nature 325(6106), 733-736 (1987).

${ }^{39}$ E. Takai, K. Kitano, J. Kuwabara, and K. Shiraki, Plasma Process. Polym. 9(1), 77-82 (2012).

${ }^{40}$ B. Demeule, R. Gurny, and T. Arvinte, Int. J. Pharm. 329(1-2), 37-45 (2007).

${ }^{41}$ Y. Yoshimura, Y. X. Lin, H. Yagi, Y. H. Lee, H. Kitayama, K. Sakurai, M. So, H. Ogi, H. Naiki, and Y. Goto, Proc. Natl. Acad. Sci. U.S.A. 109(36), 14446-14451 (2012).
${ }^{42}$ F. Meersman and C. M. Dobson, Bba-Proteins Proteom 1764(3), 452-460 (2006).

${ }^{43}$ T. Zako, M. Sakono, N. Hashimoto, M. Hara, and M. Maeda, Biophys. J. 96(8), 3331-3340 (2009).

${ }^{44}$ J. D. Fowler, J. A. Brown, M. Kvaratskhelia, and Z. C. Suo, J. Mol. Biol. 390(3), 368-379 (2009).

${ }^{45}$ M. Fandrich, M. Schmidt, and N. Grigorieff, Trends Biochem. Sci. 36(6), 338-345 (2011).

${ }^{46}$ H. Yagi, D. Ozawa, K. Sakurai, T. Kawakami, H. Kuyama, O. Nishimura, T. Shimanouchi, R. Kuboi, H. Naiki, and Y. Goto, J. Biol. Chem. 285(25), 19660-19667 (2010).

${ }^{47}$ D. L. Bayliss, J. L. Walsh, G. Shama, F. Iza, and M. G. Kong, New J. Phys. 11, 115024 (2009).

${ }^{48}$ See supplementary material at http://dx.doi.org/10.1063/1.4861842 for the preparation of amyloid fibrils and the experimental details. 